miento de señor, por la indicación de humildad implícita en su rustiquez. Es curioso notar cómo, integrada luego en el léxico del sayagués literario, al principio término de respeto hacia Dios (Encina), hacia el señor temporal y hacia los padres ${ }^{21}$, sobrevivió hasta fines del siglo, reducida al cabo a zalamería gitana ${ }^{22}$ o melindre de enamorada.

Bryn Mawr College.

J. E. Gillet

\title{
MISCELÁNEA GITANO-ESPAÑOLA
}

III. Menda y mangue en el sistema pronominal español.

En un estudio hoy difícilmente asequible, H. Schuchardt, Slawo-deutsches und Slawo-italienisches (Graz, I 885, pág. 8), fué el primero que llamó especialmente la atención sobre la supervivencia en el gitanoespañol, con uso indistinto, de tres formas de los casos de la antigua flexión indoeuropea del pronombre personal en primera persona. M. L. Wagner, Notes linguistiques sur l'argot barcelonais (Barcelona, I924, pág. 69), notaba también la coexistencia de las formas man, manda y mangue, correspondientes a los casos recto y oblicuo de la flexión gitana, en el argot barcelonés, con referencia a las formas paralelas dadas por los diccionarios de caló español y de gíria portuguesa. Wagner no ha sacado partido, sin embargo, de la confusión de estas formas en su estudio sobre "flexional confusion" en el gitano-español (JGLS, Third Series, XVI, I937, págs. 30 y sigs.). El vocabulario de G. Borrow, The Zincali (The Works, X, London, I923, págs. 422 y sig.), es cierto, había recogido las formas man, mangue y menda, pero la falta de rigor de Borrow no le permitió más que colocar las traducciones ' $\mathrm{I}$ ', ' 10 ' al lado de man y menda, y decir que mangue es "the aecusative of the pron. pers.", haciendo una referencia a man. Borrow debió pensar más -y no con gran precisión- en el acusativo complemento directo español que en el caso primitivo de que derivaba mangue. El libro clásico de A. F. Pott, Die Zigeuner in Europa und Asien, I (Halle, I844, págs. 229 y sigs.), una de las célebres monografías de F. Miklosich, Úber die Mundarten und die Wanderungen der Zigeuner, XI (Wien, I888,

${ }^{21}$ En la fórmula tradicional padre señor, madre señora. Véase sobre el particular Carvajal, Tragedia Josephina, ed. Gillet, Princeton-Paris, 1932, nota al verso 1697 .

${ }^{22}$ No se encuentra senor en el habla de las gitanas de Gil Vicente (cf. la Farça das Ciganas, Obras, ed. Mendes dos Remedios, Coimbra, I907-1914, vol. III, págs. $23^{8}$ y sigs.: señúrez, señura, etc.; Auto da Festa, vol. II, págs. 433 y sigs.: señor, señora). Verifico las citas por las Obras completas de Gil Vicente. Reimpressão fac-similada da edição de 1562, Lisboa, 1928. Tampoco se halla senor en la Farsa Ardamisa, de Diego de Negueruela, ed. Rouanet, Barcelona-Madrid, 1900: ceñor, ceñora; en el Aucto de la Huida de Egipto, Rounet, Autos, vol. II, págs. 38I y sigs.: zeñorez, zeñora; en la Eufemia de Lope de Rueda, Teatro, ed. Moreno Villa, Madrid, I924: zeñora, señora, o en su Medora, Obras, ed. Fuensanta del Valle, Madrid, i $895^{-1896}$, vol. II, págs. $25^{8}$ y sigs.; ed. E. Cotarelo, Madrid, Igo8, vol. I, págs. 27 I y sigs.: señor, señora, señores. 
págs. 24 y sigs.) y los modernos estudios de A. C. Wolner, Studies in Romanic philology, I: Personal pronouns (JGLS, New Series, IX, I9 I 5, págs. I I9 y sigs.) y J. Sampson, The dialect of the Gypsies of Wales (Oxford, I 926 , págs. I 58 y sigs.), nos dan una idea bastante exacta de la relación entre la declinación de los pronombres en los dialectos gitanos y en las lenguas antiguas y modernas de la India: los menda y mangue españoles son formas del caso oblicuo, los llamados dativos I y II, o dativo y preposicional, bastante próximos en origen y uso. EI man recogido por Borrow y el man del argot barcelonés corresponden al caso recto o nominativo, o quizás al acusativo del caso oblicuo ${ }^{1}$.

De estas formas del dialecto gitano-español, sólo de menda y man$g u e^{2}$ puede decirse que hayan pasado al lenguaje popular, donde han echado firmes raíces; man parece no existir, y una forma men, posible nominativo gitano antiguo, usada en raras ocasiones ${ }^{3}$, tal vez sea únicamente una forma apocopada de menda. La omisión del pronombre sujeto en la oración en español contribuyó seguramente de manera decisiva a la pérdida del nominativo gitano. Menda y mangue, por el contrario, son formas vivas hoy - más extendida tal vez en el lenguaje diario la primera que la segunda, por lo menos en Madrid-, y aparecen frecuentemente en obras literarias de los siglos $\mathrm{xIx}$ y $\mathrm{xx}$ que intentan reproducir fielmente la lengua hablada y el argot. Menda y mangue significan lo mismo y se emplean indistintamente. Buena prueba de ello son los textos siguientes, en que las formas menda y mangue se sustituyen y suceden en el contexto sentidas por el autor que las emplea como simples sinónimos: "Cánd.—¿Verdad que está usted por mangue? Tib.-—¿Verdad que está usted por menda?"' (J. López Silva y C. FerNÁNDEZ Shaw, La revoltosa, en Sainetes madrileños, Madrid, Ig I I,

1 A. Keller, Einfluss des Spanischen auf die Sprache der in Spanien lebenden Zigeuner, en ZRPh, XVI, I892, pág. I69, observa sin dar ejemplos ni más detalles: "Die persönlichen Pronomina haben neben dem Nominativ auch die alten Formen des Dativ, Accusativ und Ablativ erhalten; doch lebt die ursprüngliche Bedeutung derselben im Sprachbewusstsein der heutigen Zigeuner nicht fort. Ihre Deklination geschieht wie im Spanischen durch de und $a^{\text {ss }}$. Pero en su gramática del caló, F. DE S. MAyo Quindalé, El gitanismo, Madrid, I87o, pág. 57, hace aún la diferencia: menda, man, 'yo'; mangue, 'a mí.

2 A. F. Ротт, ob. cit., I, pág. 233, observa que en la traducción del Evangelio de San Lucas por Borrow aparece la forma amangue; se trata de una prefijación de la preposición a: a mangue (recuérdese la frecuente prefijación del artículo determinado $o$ en el vocabulario de The Zincali que ha sido observada con frecuencia; cf. D.MAcRitchrE, en JGLS, Old Series, III, i891-1892, pág. 63).

3 Cf. un ejemplo en un cantar en caló "cerrado" en El Bachiller Kataklá, Cantos gitanos, Logroño, 1907, pág. 73

$$
\begin{aligned}
& \text { Terela men calorri } \\
& \text { os clisos e agrijiné } \\
& \text { y e galuchí a retuñi. }
\end{aligned}
$$

La construcción de men con la tercera persona de singular del verbo hace pensar fundadamente que es una forma apocopada de menda y no un antiguo nominativo. Lo mismo ocurre con los men que aparecen en los cantos flamencos recogidos por G. Borrow como apéndice a The Zincali ( $\mathrm{cf}$. infra, nota 8). Men aparece siempre en esos cantares en la construcción su men que el propio Borrow interpreta en el vocabulario: 'your lordship', 'usted', después de explicar men 'person, honour', 'persona, honor', como palabra derivada del sánscrito. Esta, como otras muchas conjeturas de Borrow, parece dudosa. 
pág. 9o ); "Todo ha sido porque menda-decía don Faustino- llevó a la corrida al francesito ese, porque Antonio por indicación de mangue le brindó el quinto..." (F. Mora, El patio de Monipodio, Madrid, I9 I 2, pág. 7 I ).

Grandes escritores contemporáneos que han dado cabida en su lenguaje a palabras de caló emplean lo mismo una que otra forma. ValleInclán parece dar alguna preferencia a menda: "-iMenda se naja denantes!..." "-Para menda, queda" (Viva mi dueño, Madrid, I928, págs. 249 y 253); "Así te despeines o te subas el moño, para menda lo mismo que la Biblia del Padre Carulla..." (Tirano Banderas, Barcelona, I 938, pág. I 89). Pero también usa la otra forma: "Don Latí se va a la calle de ganchete con mangue" (Luces de bohemia, Madrid, 1924, pág. 294). Salvador Rueda usa asimismo mangue: "Las cantaoras, los bailaores... y mangue" (La guitarra, en El cuento semanal, I, 19.7, pág. I).

Menda y mangue, formas de un antiguo caso oblicuo, penetraron en el uso español a través del complemento con preposición (el "caso terminal" de Bello) al amoldarse el gitano al sistema de la flexión española. Es decir, que sustituyeron fácilmente a la forma $m i$, sin afectar para nada al complemento sin preposición me (el "caso complementario", directo e indirecto, de Bello). Este uso es el más frecuente, y hay textos numerosos que patentizan lo arraigado del mismo. Véanse, además de los citados, entre muchos, T. Rodríguez Rubí, La feria de Mairena (Madrid, I857, pág. 22): "Esa prenda / está rescatá por mangue"; J. López Silva y J. Jackson Veyán, El barquillero (Madrid, I 9o I, pág. 35): "¡Y too pa mangue!”; G. Corrochano y R. FernánDEz Murrieta, La gitanada (Madrid, I9I4, pág. 22): "Lo que es $p a$ menda / no se peina usté"; etc. Pero en algunos de los ejemplos primeramente citados hemos visto que menda, mangue aparecen como sujetos de la frase. Esto no quiere decir, sin embargo, que las formas gitanas sustituyan al yo: menda y mangue son voces demasiado ajenas al sistema pronominal español, y el yo sujeto de una oración es demasiado fuerte para que los gitanismos aparezcan en el lugar del nominativo del pronombre personal de primera persona. Menda y mangue se construyen con la tercera persona de singular de los verbos, y esta concordancia revela cómo su asimilación al cuadro de los pronombres españoles no ha sido completa. Están de algún modo en lugar de yo, pero no del todo .

4 Lo mismo ocurre con las deformaciones pronominales del argot francés. Sustituyen exclusivamente la forma tónica moi y las diversas voces de vieja tradición que da L. SaInéan, Le langage parisien au xix siècle, Paris, I920, págs. 5 I9 y sigs.: mézigue, mézigo, monière, mogniasse, monorgue, etc. (y, junto a éstas, formas para la segunda y tercera persona: togniasse, sonorgue, tonguere, etc.), como sujetos se construyen con la tercera persona de los tiempos verbales. Sainéan observa que "les particules deformatives -nière ou -gnière et -orgue sont devenues à leur tour des moms au sens de l' 'individu', et de 'personne', d' 'homme" " $\mathrm{y}$ "de même gniasse, abstrait de moniasse ou soniasse, moi ou lui". Eso confirma que los sufijos se sentían siempre como elementos extraños al pronombre. Algunos de esos sufijos aparecen como palabras independientes en el vocabulario apéndice de H. BAuche, Le langage populaire, Paris, 1929, pág. 225: gniasse, "mon gniasse", "ton gniasse", etc. 'moi', "toi'; pág. 256: zigue 'homme', 'brave homme’. Cf. 
A veces menda y mangue parecen hasta desempeñar en el lenguaje conversacional el oficio del llamado "yo enfático", como en los ejemplos que siguen, pero la concordancia evidencia siempre lo extraño del sujeto: "Gir.—¿Pero tó es chipén? / Pos.-Menda lo dice" (G. L. OlmeDo y G. Escobar, Maldición gitana, Madrid, I go2, pág. I 7 ); "Como si quién ustés que vaya menda pa echar una mano..." (A. Torres DE L Álamo y A. Asenjo, La romántica, Madrid, I9 I 4, pág. I 3); "Mangue, cuando encuentra un payo como tú, lo ziente de verdá ..." (EL CABALlero Audaz, Lo que sé por mí, $1^{\mathrm{a}}$ serie, Madrid, I9 I5, págs. $25^{\circ} \mathrm{y}$ $\left.25^{2}\right)$.

La mezcla en un texto de las formas pronominales españolas con las gitanas contribuye a la confusión de las mismas, aunque menda y mangue sigan diferenciados por su especial concordancia: "Camela mangue a una gachi / lo más barbiana y más cañi / que me va a dar su garlochí, / pues su cariño es de chipén pa mí" (A. Torres del Álamo y A. Asenjo, La boda de Cayetana o Una tarde en Amaniel, Madrid, 19 I5, pág. 32).

A veces, en la combinación tú + yo $=$ nosotros, menda ocupa el lugar del pronombre de primera persona con el verbo en plural: "Ya no hay toreros ni toros / más que tú y menda, que semos / un par de gacholis de esos / que hacen sombra..." (J. López Silva, Migajas, Barcelona, s. a., pág. I o6).

En alguna ocasión menda y mangue parecen ir avanzando en el camino de reemplazar todos los usos y casos de yo en el sistema pronominal español. Vimos cómo nuestros gitanismos no sustituían a las formas átonas del pronombre, pero sí aparecían sustituyendo a las formas tónicas del mismo. La circunstancia de que el español, por razón de la evolución histórica de sus formas verbales, no haga distinción entre el yo sujeto del verbo y de la oración y la forma pronominal con que se afirma la propia esencia y existencia, formas correspondientes al francés $j e, m o i$, o al inglés $I$, me, myself (nótese también la tendencia diferenciadora que en el inglés coloquial sustituye la forma libresca it is $I$ por un it’s me), dió pie a una nueva irrupción de menda, mangue en el campo de los pronombres españoles. Así encontramos a menda, mangue, siguiendo fielmente el uso español, reemplazando al yo, forma tónica del pronombre, con que se contesta a una pregunta: "—¿Quién pide la palabra? / -Menda" (J. LóPez Silva, Los barrios bajos, Madrid, I9I I, pág. 3 I) ; "Luc.-¿Quién lo ha dicho? / EPIF.-Mangue" 5 (J. López Silva y C. Fernández Shaw, Las bravías, en Saínetes madrileños, Madrid, I9 I I, pág. Io).

Y también encontramos a las formas prominales gitanas sustituyendo a yo en la comparación, debido a la misma carencia de medios diferenciadores (cf. fr. mieux que moi, ing. like me): "Un artista de verdaz / como mangue ..." (J. López SiLva, Los Madriles, Madrid, i 896,

también las observaciones de E. Rianter, Umschreibungen des Personalpronomens, en $N S p r$, XXXIX, I93 I, págs. 280 y sigs.

5 Claro que la sustitución no es aquí tampoco absoluta: podrían concebirse las respuestas como menda la pide, mangue lo ha dicho. Pero es un hecho que menda, mangue aparecen aquí en lugar de yo. 
pág. I 35); o bien, con una preposición, oponiéndose a otro pronombre personal: "Gitana, entre menda y tú / hay la mesma deferencia / que hay entr'er diablo y la crú" (El BaGhiller Kataklá, Cantos gitanos, Logroño, I907, pág. 46).

Pero menda, mangue no pasaron de ahí ${ }^{6}$. Claro es que mal podían acabar de reemplazar a yo sujeto de una oración cuando este yo aparece tan rara vez en el uso absorbido por la desinencia de la forma verbal (de hecho, los pronombres fr. je e ing. $I$ han quedado inutilizables como formas pronominales independientes ${ }^{7}$ ). Pero sí en algún caso aislado parece como si menda, mangue forzaran a la frase española a entrar en un molde poco normal imponiendo el complemento preposicional ("no conoce a mí" en lugar de "no me conoce"), aunque el mismo contexto del siguiente ejemplo demuestre el verdadero valor de mangue: "¿Y usted no conoce a mangue? / ¿Y mangue es este cura?" (G. PeRRín y M. DE Palacios, Las castañuelas, Madrid, ig I5, pág. 25).

Las formas pronominales gitanas, en el fondo, no son sentidas, desde el punto de vista del hablante, más que como sustitutivos de una serie de expresiones que sirven para evitar la alusión a la propia personalidad. O, mejor, como una más de esas expresiones de tercera persona que abundan en el lenguaje popular español, y hasta en las fórmulas del lenguaje burocrático y epistolar, en lugar de yo: (su) servidor, servidorito, uno, este tío, el aqui presente, etc.; el este cura del último texto citado es también frecuente: mangue, hemos visto, constituye un perfecto equivalente suyo. En muchas ocasiones, por el contexto o las especiales circunstancias a que se refiere el hablante, menda, mangue dan la impresión de perder bastante de su carácter de pronombres personales para expresar más bien el sujeto general e indeterminado uno, tan frecuente en el lenguaje conversacional español. Así, por ejemplo, podrían interpretarse los textos siguientes: "Manque gorviera mangue a rezuzitá..." (J. Velázquez y Sánchez, El brazo de Dios, I, Sevilla, I 846, pág. 55); "San creío los gaché / que mangue es aquí profeta..." (F. Gómez SÁnchez, Las travesuras de Juanelo o Un día de toros, Málaga, i 863, pág. 21 ); "Y menda va pensando / si los toreros / se habrán ido enmendando / o vendrán hueros" (copla de un periódico taurino citado por E. Noel, Piel de España, Madrid, I9 I7, pág. 3I ).

De ahí que esos gitanismos puedan impersonalizarse destacándose por

6 Tal vez en el caló puro la sustitución puede haber sido más completa; cf. J. Brown, Nights and days on the Gypsy trail, New York, 1922, pág. 57, que transcribe una frase pronunciada por una gaditana: "Min bato sinela Bu'no, pero menda sinelo caló como min dai". Borrow, en su traducción del Evangelio de San Lucas, Embéo e Majaro Lucas, s. 1., I837, no vacila tampoco en hacer concordar menda y mangue con la primera persona del verbo: cf., por ejemplo: XI, 9: "Y menda penelo a sangue: manguelad y se os diñará"; XV, I8: "Mangue ardiñelaré y chalaré al betusch y le penaré". En los cantares que publica al final de The Zincali se da idéntica concordancia: "Pen que mangue monrabelo..." (núm. LXXIX); "mango (sic) me chalo a mi quer..." (núms. Lxxx y LXXXII). A. Alcalá Venceslada, Vocabulario andaluz, Andújar, I934, pág. 250, se confunde cuando dice que mangue es "usado en I" persona"; el ejemplo citado es: "mangue no va..." (en la pág. 262: "menda fué quien...").

$\because$ M. von Wartburg, Problèmes et méthodes de la linguistique, Paris, 1946, pág. 6o, los califica de "prefijos" o "signes de flexion" en su función actual je, tu, il. 
completo del sistema pronominal y pàsando a significar 'uno' en cada uno (más exactamente cada quisque, en el lenguaje popular), como en este ejemplo: "Total, o en totá, como él dice, que para hablar con él hay que saber la jurisdicción de cada mangue..." (E. NoEL, España nervio a nervio, Madrid, 1924, pág. I5I).

Los casos un poco sospechosos de su men que se dan en los cantos flamencos que incluyó G. Borrow como apéndice a The Zincali y el ejemplo moderno de mi men que transcribimos a continuación tal vez puedan interpretarse como formas apocopadas de menda que entran a formar parte, impersonalizadas, de calcos lingüísticos de las expresiones españolas su señoría, su merced, mi persona: "Si min dai abillara / a dicar a su men..." "No sinela su men min dai / la que me chindó..." 8 (núms. LI y LXI; cf. la ed. de The Zincali, London \& New York, 1902); "- iTe sentirás el lunes patriotero? / -No puedo complacerte, Graciliano; / nos la hemos cortao al mismo tiempo / Vicentillo y mi men" (A. Torres del Álamo y A. Asenjo, Postinerías, Madrid, s. a., pág. I55).

No es ahora el momento de abordar la cuestión de cómo los gitanis-

${ }^{8}$ El cantar núm. LI ofrece dificultades de interpretación. Constituyó un problema para H. Schughardt, Die cantes flamencos, en ZRPh, V, I88I, pág. 258 , que, siguiendo sus pesquisas para identificar los cantares en caló de The Zincali con otros en español anteriores a su "gitanización" por los aficionados a las costumbres, cante y baile de los gitanos, los comparó con los coleccionados por A. Machado Álvarez (Demófilo) para demostrar lo insostenible de la traducción de Borrow: "Das Englisch lautet hier so komisch, dass ich es mitteilen will:

Sir Cavalier, my mother dear

Must come and visit you.

That mother dear, Sir Cavalier,

The face of God may view."

En efecto, la traducción es disparatada. Compárese con los textos originales completos:

\author{
Si min dai abillara \\ a dicar a su men, \\ yo le pensara que fuera \\ con Dios Undebel.
}

\author{
Si la mare e mi arma \\ biniera a buscarme, \\ yo le igera: baya osté con Dios, \\ que osté no es mi mare.
}

Schuchardt añade: " $A$ su men heisst allerdings 'Euere Gnade'; aber das gibt im zweiten Vers gar keinen Sinn und gehört in den dritten; dort muss ein Wort stehen, welches auf den Sprechenden weist (a mangué, 'mich' assonirt allerdings nicht mit Undebel)". Schuchardt interpreta también el significado de "mandar a alguien con Dios" en español ('gehen Sie zum Teufel') para demostrar la imposibilidad de la traducción de Borrow, y relaciona este cantar con otros (especialmente con el núm. LXI) que, por el tema, tienen que ver con el núm. LI. Pero "No sinela su men..." se compagina mal con el su men del primer cantar, y éste a su vez con el ejemplo moderno que se cita en el texto: mi men. Pese a toda la sagacidad de Schuchardt, el problema sigue en pie, pendiente de una verificación de la etimología borrowiana: men 'honor' no parece existir en gitano, y la interpretación 'persona' se debe tal vez a una confusión o cruce con otra voz gitana, otro gitanismo: manu 'hombre'. Un ejemplo antiguo de F. Gómez Sánchez, La for malagueña ( $3^{*}$ ed., Málaga, I861), que cita Schuchardt, pág. 268: "El lenguaje e la gracia: / ¿Pues no lo chama sumé?", parece sugerir también un calco sobre su merced, tratamiento muy vivo todavía en la región andaluza durante el siglo xix. 
mos han penetrado en el lenguaje popular español. El afán de hacer hablar a los gitanos en su jerga en los libros y en la escena, el éxito del teatro costumbrista andaluz del siglo xix y aun en nuestros días, la afición siempre renovada a lo "flamenco" en todos sus aspectos, el "flamenquismo" en las costumbres y lenguaje de "los hijos del pueblo de Madrid" acentuado por los saineteros, el uso de vocabulario gitanesco en la prensa, especialmente la taurina, etc., han sido razones y caminos a través de los cuales las voces gitanas adquirían carta de naturaleza en el lenguaje popular español ${ }^{9}$. Los pronombres gitanos formaban parte de ese léxico "flamenco" que paulatinamente iba siendo acervo común de los españoles: En una antigua comedia andaluza de R. Sánchez del Arco, Tal para cual o Lola la Gaditana, Cádiz, I851, pág. 2 I, se propone componer adrede una copla "flamenca" en caló y mangue no deja de ser uno de los ingredientes: "Mira tú, hazle una copla salada: Mangue en yes coro desnó ..." Eugenio Noel, el debelador contemporáneo del "flamenquismo", en uno de sus múltiples ataques a sus tipos y su lenguaje, escribe en Señoritos, chulos, fenómenos, gitanos y flamencos, Madrid, 1916, pág. 321: "Andan a lo torero, hablan a lo chulo, tienen un caló en el que la palabra mangue es una cosa tenebrosa ..." Esas etapas fueron las que llevaron a las formas del pronombre personal gitano de primera persona a su naturalización dentro del sistema pronominal español.

En uno de sus libros observa el filólogo danés O. Jespersen que muy rara vez pasa un sistema pronominal de una lengua a otra, y que muy rara vez también pierde una lengua sus pronombres fuertemente ligados a la trama más íntima y esencial del idioma ${ }^{\mathrm{T} 0}$. Por eso conservaron los gitanos las formas del caso oblicuo de su antigua flexión hasta cuando su dialecto se convirtió en mero español agitanado. $Y$ por eso opuso también resistencia el español a identificar por completo mangue y menda con el pronombre yo. En otro de sus libros habla Jespersen de "notional and grammatical person" "I y de los conflictos que en diversas lenguas se presentan entre ambas —entre ellos, en el español, el que se da entre el pronombre de primera persona y alguno de los sustitutivos de tercera persona que antes mencionamos; el de vuestra merced, usted, tercera persona que ocupa el lugar de $t u$ y vos - : menda y mangue son, en fin, distintas "personas gramaticales" de un "nocional" yo. No hay que olvidar tampoco que menda y mangue parecen haberse identificado en el uso diario con el pronombre indefinido uno y que este uno viene a confirmarse, después del minucioso estudio de S. Kärde, como "simple variation stylistique de yo" ${ }^{\prime 2}$. El lenguaje popular ha encontrado, pues,

9 Cf. algunas observaciones sobre el particular en mis estudios Gitano andaluz "Devel", "Undevel", RomPh, I, I948, págs. 33-6I, y En torno a una frase en "caló" de Don Juan Valera, HR, XVI, I948, págs. 97-I I.

${ }_{10}$ Die Sprache, ihre Natur, Entwicklung und Entstehung, Heidelberg, I925, pág. I93.

11 The philosophy of grammar, London, 1925, págs. 215 y sigs.

12 Quelques manières d'exprimer l'idée d'un sujet indéterminé ou général en espagnol, Uppsala, I943, págs. 35 y sig. 
por todo ello, en los gitanismos menda y mangue, un buen recurso estilístico que ensancha los ámbitos del sistema pronominal de la lengua española.

University of Pennsylvania.

Garlos Clavería

\section{JORNADA (La casa de los celos, II)}

Ángel Valbuena Prat, en su breve introducción a La casa de los celos publicada en su edición de las Obras completas de Cervantes ${ }^{\mathrm{I}}$, dice que esa comedia "hace los efectos de ser refundición de un texto anterior y de la primera época del teatro de su autor. Es curioso un detalle que se escapó a Cervantes al refundir la comedia. En el acto segundo, las palabras del Amor:

$$
\begin{aligned}
& \text { y esto dicho, el fin se llega } \\
& \text { de dar fin a esta jornada, }
\end{aligned}
$$

indican claramente que se trata de un fin de acto. $\mathrm{Y}$, sin embargo, la jornada continúa algún tiempo, denotando que se trata de un zurcido"' (pág. 252). La opinión de Valbuena probablemente derive de Schevill y Bonilla o de $E l$ teatro de Cervantes de Cotarelo y Valledor ${ }^{2}$, quien a su vez acusa a Cervantes por ello de descuido e improvisación. Pero una mejor lectura del pasaje nos dice que jornada no significa allí 'acto de comedia', sino su objeto originario de 'camino de un día', 'viaje', entonces corriente ${ }^{3}$.

Este fin de jornada cervantino aparece en un episodio en que las Divinidades del Amor vienen a la tierra a mezclarse en los asuntos amorosos de los mortales.

"Aparece en este instante el carro de fuego tirado de los leones de la montaña y en él la diosa Venus" (pág. 275). En seguida, invocado por Venus en socorro de Reynaldos, abrasado de celos, acude también a la tierra Cupido, viajero en una nube. Cupido promete el olvido al desdi1946.

1 Miguel de Cervantes, Obras completas, ed. A. Valbuena Prat, Madrid,

2 A. Cotarelo y Valledor, El teatro de Cervantes, Madrid, 1915, pág. 495. Schevill y Bonilla no anotan el pasaje (Comedias y entremeses, I, pág. igo, línea 13); pero en la Introducción, publicada en el tomo VI y último, Madrid, 1922, pág. I Io, dicen los editores: "Indicios existen de que esta comedia tuvo originariamente otra forma. Quizá constaba en un principio de más de tres jornadas". Y en la nota: "Véase la pág. 19o, líneas 12-13 del tomo I de nuestra edición de las Comedias y entremeses", o sea el mismo pasaje que aquí nos ocupa.

3 El Tesoro de Covarrubias trae todas las acepciones importantes de jornada menos la teatral. El Diccionario de Autoridades, todas las incluidas en los diccionarios modernos. Carmen Fontecha, Glosario de voces comentadas en ediciones de textos clásicos, Madrid, 1941, s. v. jornada, registra cuatro comentarios a esta significación de jornada (o a la de 'expedición de fuerzas armadas'), empezando por uno de Clemencín, Quijote, III, 404. A la mano está multiplicar los ejemplos, pero me contentaré con aducir uno de Quevedo en el que juega con la doble significación de 'camino de un día' y 'acto": "Comenzó a recitar una comedia que tenía más jornadas que el camino de Jerusalén" (Buscón, ed. A. Castro, Madrid, 1911, pág. ro8). 